\title{
THE CONSTITUTION OF THE NOT- FOR-PROFIT ORGANISATION: RECIPROCAL CONFORMITY TO MORALITY
}

\author{
Gianluca Grimalda \\ and \\ Lorenzo Sacconi
}


The Discussion Paper series provides a means for circulating preliminary research results by staff of or visitors to the Department. Its purpose is to stimulate discussion prior to the publication of papers.

Requests for copies of Discussion Papers and address changes should be sent to:

Dott. Stefano Comino

Dipartimento di Economia

Università degli Studi

Via Inama 5

\author{
38100 TRENTO ITALY
}




\title{
The Constitution of the Not-For-Profit Organisation: Reciprocal Conformity to Morality
}

\author{
Gianluca Grimalda and Lorenzo Sacconi*
}

October 2004

\begin{abstract}
We investigate the link between individual motivations and economic organisations by focusing on the case of non-profit firms. First, we provide a model of individual behaviour that allows for agents to have motivations different from self-interested ones. We assume that individuals desire to comply with the prescriptions of a universally recognised moral principle conditionally on the expectation of alike compliance by other agents. This principle will shape the constitutive ideology of the non-profit organisation. Second, we study a simple 'production game' where a 'for-profit' and a 'non-profit' equilibria both exist. In the former, self-interested considerations prevail, so that agents implement the free-market standard; conversely, in the latter, conformist preferences are dominant, so that players act in such a way that the moral principle is fulfilled. The non-profit organisation is then characterised in terms of a 'social contract' between the founders of the firm and its stakeholders. We also point out that the structure of the 'psychological game' underlying the interaction is akin to a co-ordination problem, so that the possibility of co-ordination failures underscores the risk of 'distorting' individual dispositions in the shift from the 'micro' level of the individuals to the 'macro' level of the organisation as a whole.
\end{abstract}

Keywords: Non-profit, non-self-interested motivations, conformism, reciprocity, ideology.

JEL Classification: L31, D11, D63, Z13

\section{Acknowledgements:}

We thank Luciano Andreozzi, Emma Baldin, Marco Faillo, Alan Hamlin, Luigi Mittone, Robert Sugden, Roberto Tamborini, an anonymous referee, and the participants in the International Conference "The Paradoxes of Happiness in Economics" (Milan, University of Milano-Bicocca, 21-23 March 2003), the EAEPE Conference "Comparing Economics institutions" (Siena, 8-11 November 2001), and seminars in Trento for their comments. Usual disclaimers apply.

\footnotetext{
- Forthcoming in Costitutional Political Economy (2005)

* Centre for the Study of Globalisation and Regionalisation (CSGR), Warwick University

** Department of Economics, University of Trento and CELE, Centre for Ethics, Law and Economics, University Cattaneo LIUC, Castellanza
} 


\section{INTRODUCTION}

The existence of forms of productive organisation that purposely eschew the logic of profit maximisation calls for a redefinition of both the motivations held by the individuals involved in them and the goals of the organisation as a whole. It is clear that none of these 'agents' follows the traditional paradigm of homo-economicus ${ }^{1}$ in the context of non-profit activities. But then the problem arises as to what can be defined as the 'objective' of these agents. To be sure, answering this question may help shed some light on the much-debated issue of the nature and function of the non-profit organisation (henceforth NPO) vis-à-vis for-profit ones (FPO).

According to one of the two main strands of literature addressing the non-profit case, entrepreneurs involved in running NPOs are 'ideologues' (Rose-Ackermann (1987), (1996)), that is, they are committed to the principles of a given 'philosophy of service', i.e. a mission to provide and distribute some welfare good according to a moral principle. Under the ideologues' approach, the organisational 'mission' is a value per se, rather than being instrumental to achieving a further good or to fulfilling further interests, such as maximizing profit. Although intuitive, however, this recourse to ideology seemingly takes us far from the typical economic explanation based on methodological individualism, since ideology is usually claimed to be a social artefact presupposed, rather than explained, by individual choices in that it shapes the social identity necessary to define the choice systems of individuals. As such, resorting to 'ideology' seems contrary to the idea typical of the 'constitutional economy' approach to institutions that an institution (such as an organisational form) emerges from the interaction among rational individuals.

In order to reconcile the 'ideologues' approach with an explanation based on individual action, it is typically maintained that individual agents in NPOs have personal motivations which extend beyond mere 'self-interested', even though there is still little consensus as to what such 'non-selfinterested'- or, as they are frequently called in the literature, other-regarding - preferences actually are. The most direct and simplest solution, which is also present in Rose-Ackerman's works, is to assume that 'ideologues' stick to the ideological mission of the enterprise, even if this is contrary to their self-interest, because they are 'altruistic', which of course accommodates both their 'others-oriented' attitude and that of the organisation as a whole. ${ }^{2}$ However, the resort to the assumption of altruism may in a way appear as question begging, and it also seems at variance with the factual evidence coming from the flourishing literature in experimental economics. This

\footnotetext{
${ }^{1}$ We here interpret the paradigm of homo-economicus as requiring both instrumental rationality and the pursuit of an agent's self-interest. Hence, an agent who behaves as a maximiser of an objective function different from self-interest could not, in our definition, be called a homo-economicus.

2 The other 'economic' approaches to the non-profit enterprise originate from the seminal contributions by Weisbrod (1988) and Hansmann $(1980,1988)$. They emphasise the failures of both the political and the market system to provide public or welfare goods, due to inefficiencies in political mechanisms (i.e. the choice made by the median voter necessarily leaves some demand 'unsatisfied') and to the information asymmetry intrinsic in the donor-recipient relationship. Hansmann's theory satisifies both methodological individualism and new institutionalism in that it deduces the necessity of an institutional 'non distribution constraint' (such that non profits are 'firms without owners' in the strict sense) from the transaction costs that would arise from strategic behaviour between principals (the donors and the beneficiaries) and agents (the producers) under radical information asymmetry. However, this explanation does not clarify why selfinterested actors would undertake the development of this kind of productive organisation, so that it also requires the existence of some actors driven by non self-interested motivations. Moreover, it is not a 'constitutional' explanation, because it does not say how non-profit institutions are able to emerge endogenously from the interaction among rational agents, rather than being imposed externally by a legal order.
} 
emphasises that, in spite of the presence of some altruistic traits in human behaviour ${ }^{3}$, the overall picture of human motivations is much more complex than what implied by altruism. In fact, altruism seems to be inescapably intertwined with a disposition to reciprocate the intention perceived in others' actions, so that it may often revert to its opposite, i.e. defection and even revenge, if not upheld by a sufficiently high proportion of agents of the group ${ }^{4}$. Moreover, a second motivational trait, given by the concern with some notion of fairness in the payoffs allocation, seems to emerge with substantial regularity out of experimental evidence. This leads agents to perform 'altruistic' actions towards less fortunate agents in the payoffs distribution, but also to execute unkind actions towards agents who have acquired larger shares. ${ }^{5}$ Hence, inequity aversion, envy of income differences, and other hypotheses that are generally referred to as 'social preferences' are all instances of a much more multi-faceted picture of human behaviour than that implied by mere altruism. In the light of this evidence, it is apparent that RoseAckerman's tradition, right though it is in basing the character and performance of organisations such as NPO on individual motivations, needs to be innovated by adducing more sophisticated patterns of 'other-regarding' behaviour than those implied by mere altruism. This observation will form the basis of our analysis of the NPO. Our aim is thus to offer a new insight into the nature of the NPO by relying on a more general model of individual behaviour than those available in the literature.

The paper is organised as follows. In section 2 we develop a formal model of individual choice, in which both self-regarding and other-regarding motivations are considered within a comprehensive utility function. More specifically, the latter combines both intention-based reciprocity and social preferences in what we shall label conformist preferences, where we assume that an individual desires to comply with the prescriptions of a rationally acceptable moral principle conditionally on the expectation of similar compliance by other agents. The resulting preferences have a specific deontological character that makes them different from standard consequentialist preferences.

The paper then builds on this model in order to investigate the relationship between the 'micro-level' of individual motivations and the 'macro-dimension' of the character and performance of the organisation, thereby accounting for the emergence of the non-profit institution vis-à-vis the for-profit one. Section 3.1 develops a simple 'game of production' where

${ }^{3}$ The clearest evidence supporting this view is the observation of positive levels of giving in the so-called Dictator Games; see e.g. Charness and Rabin (2000), Andreoni and Miller (1993).

${ }^{4}$ This feature emerges most clearly in repeated Public Good Games. Co-operation generally starts off at considerably high levels, as the public good is provided at about 40-60 percent of the optimal quantity in the first instance of the game, but then progressively declines over its repetitions. Nevertheless, in the last instance of the game the public good provision is usually not inferior to $10 \%$ of the socially optimal level, which shows that a non-negligible proportion of subjects is purely altruistic - or perhaps irrational (Dawes and Thaler (1988: 189)). Nonetheless, what appears to explain the observed behaviour in co-operation is that a sizeable proportion of subjects are conditional co-operators, who switch to defection as they realise that others' co-operation is inferior to their expectations (Croson (1999)). Alongside these 'types' there stand selfish individuals, who either always defect, or may use co-operation as a strategic device to elicit co-operation from other individuals, and then free-ride (see Kreps et al. (1982)). The impact of 'group spirit' on co-operation has also been investigated (Dawes et al. (1988)). This is reached through making it possible for subjects to talk before the game takes place. The authors notice that in groups in which promising is not universal there was no relationship between each subject's choice to cooperate or defect and (1) whether or not a subject made a promise to cooperate, or (2) the number of other people who promised to cooperate.'

${ }^{5}$ Punishment of actions perceived as 'unfair' is nearly always observed in experiments. The most typical example is the positive degree of rejection of Responders in Ultimatum Game - e.g. Guth et al. (1982), and the introduction of a punishment stage in a public goods game, which, surprisingly enough, is capable of bringing about nearly universal co-operation (Fehr and Gachter (2000)). 
an entrepreneur and a worker of a would-be firm have to decide their degree of commitment to the firm's activity. In particular, each of them can either decide to conform to a pre-existing freemarket standard, or to execute a costly action in terms of their material interests, which nevertheless increases the surplus of an external beneficiary, e.g. a consumer of the good produced. Section 3.2 models the NPO constitutional ideology as having a contractarian character, and the Nash social welfare function is adopted as the shared moral principle that gives normative content to agents' conformist preferences. What is notable for the NPO case is also that the ideal social contract that underlies the mission of the NPO includes the beneficiary of the productive activity in the assessment of the fairness of the allocation, although she only is a 'dummy player' in the actual game.

Section 4 analyses the production game in terms of psychological game theory, which extend the standard equilibrium concepts to the case in which players' preferences depend on expectations on each other's behaviour (Geneakoplos et al, (1989)). We show that both a 'nonprofit' and a 'for-profit' equilibria exist. In the former (section 4.1), conformist preferences are dominant, thus players select the action that fulfils to the maximum degree the prescriptions of the moral/ideological principle accepted ex ante by the players. This also implies the maximisation of the surplus accruing to the consumer of the good, whose payoffs are affected by the outcomes of the internal players' interaction. These features are what we associate with the constitution of an NPO. In the latter (section 4.2), self-interested considerations instead prevail, so that agents execute the actions consistent with the free-market standard.

We show that the presence of a sufficiently strong disposition to act in accordance with a constitutional principle of morality is a necessary - though not sufficient - condition for the nature of the firm to shift from profit- to non-profit-oriented. However, the strategic situation being akin a co-ordination game, the FPO outcome may still arise as equilibrium even when agents' other-regarding disposition is so strong as to make the NPO the Pareto-dominant outcome. This is the case when each agent's initial expectation attaches a relatively high probability to the counterpart's engaging in the self-interested action, which obviously makes this action the more convenient one for both individuals. This is a clear example of a 'self-fulfilling inefficient equilibrium' triggered by 'misleading' initial expectations, and well known is the inability of game theory to provide answers to this unpleasant feature of co-ordination games. As classic investigations into the issue show (e.g. Lewis (1969)), the only way out in order to coordinate expectations on the efficient outcome would be the introduction of cognitive elements somehow 'external' to the basic structure of the game that act as 'focal points', but that this is possible is obviously far from granted, especially in the more complex - but more realistic than the one treated in the paper- situation of uncertainty over the 'type' of the other player.

This analysis emphasises that the relationship between the 'micro' and the 'macro' dimension is by no means simple and direct as one might think. In fact, despite the apparent simplicity of the interaction depicted in the game of production, a distinctive type of what we call 'organisational failure' may arise as a result of the multiple equilibria present in the game. This is the case when, given agents' preferences and their disposition to comply with the ideology, an organisational setting that is Pareto-inefficient emerges as equilibrium of the game. Indeed, the complexity of the interactions among individuals, the absence of initial information able to coordinate initial beliefs on the efficient outcome, the particular individual attitude to condition their compliance with the 'mission' of the organisation on others' compliance, are all factors that imply that the 'character' of the organisation as a whole may not be a mere 'arithmetic average' of the dispositions of the agents participating in it, but rather a much more intricate function of them. In particular, the shift from the individual to the aggregate level may well 'distort' the individual preferences taken singularly, owing to the complexity of the web of reciprocal expectations on which agents base their decisions. 
In a wider perspective, one can thus 'read' the interactions among individual players in our model as being 'constitutional' in a sense reminiscent of the Constitutional Political Economy approach (Buchanan (1988)) - even though the 'constitutional' source of ideology in our model is more akin to 'normative' models of social contract, based on various versions of bargaining game theory (i.e. Gauthier (1986), Binmore (1997)), than it is to the 'positive' account of constitutional contract originally put forward by James Buchanan (1975). ${ }^{6}$ In fact, such interactions directly shape the nature of the organisation, rather than being constrained by them. That is, as Brennan and Hamlin (2002) put it, the emergence of the NPO is here seen as a choice among rather than within rules by individuals. Moreover, the emphasis on 'non-self-interested' preferences reveals that our approach is somehow analogous to the so-called expressive constitutionalism approach initially put forward by Brennan and Lomasky (1993). Notwithstanding the major differences between political vis-à-vis economic institutions, Brennan and Lomasky's attempt to innovate the classic problem of constitutional choice by extending the range of individual motivations to more complex forms than mere self-interest is in fact comparable to ours in the field of economic organisations. It is therefore no coincidence, we believe, that their stress on the 'intrinsic' character of expressive action bears a clear resemblance to our conformist preferences, which have in fact a distinctively 'deontological' character. Despite the different fields of application of the two theories, therefore, common to both is an endeavour to ground the character of institutions, be they political or economic, on a motivational 'micro-foundation' which spans a wider range of motivations than mere self-interest alone.

\section{A Model of Individual Motivations}

\subsection{Modelling Multiple Motivations}

The idea that individuals take account of a large number of reasons to action when making decisions - reasons which extend well beyond the stereotypical self-interested motive - is now widespread among students of rational choice. As Binmore puts it (1994: 19), 'not even in Chicago are the views [that homo-economicus strictly abides by her own self-interest] given credence any more'. This consensus paves the way for a new approach to economic modelling that may be called 'multiple motivations'-based. This is characterised by the inclusion of so-called other-regarding motivations along with the standard self-interested one within the set of ends - or desires - that an individual supposedly pursues when making decisions. Although some scholars are still doubtful as to whether this approach is the best strategy to handle empirical evidence contrary to the homo-economicus view - e.g. Binmore et al. (1995) - it is on such a framework that we intend to base our model. Contrary to other approaches that question the supposedly 'rational' character of individual choice (see e.g. Nelson and Winter (1982); Anderson et al. (1988)), the presumption here is that individual behaviour can still be accounted for in terms of rationality once the set of principles that supposedly motivate the individual has been clearly specified. Rationality is to be understood here as consistency of choices with respect to a well-specified system of individual motives to act, rather than as the pursuit of self-interest. In this sense, the utility function has no intrinsic meaning apart from being a formal device to represent such a coherent system of choice (Broome (1999: Ch. 2)).

\footnotetext{
${ }^{6}$ Our constitutional ideology emerges form a somewhat ideal bargaining situation that resembles Gauthier's hypothesis of a moralised status quo and the 'veil of ignorance' hypothesis as reinterpreted through the invariance of the solution under symmetric permutation of the players' utility functions (Binmore 1997). Buchanan (1975) is more 'realistic' in admitting inequality of forces in the original bargaining situation and inequality of endowments resulting from the 'natural equilibrium'.
} 
This is the approach taken by many experimental - or behavioural - economists, who in this way endeavour to make sense of empirical evidence yielded by laboratory experiments. In their specifications, the standard self-interested motive is 'augmented' by a variety of 'social preferences or 'intentions-based' motivations that make up an 'extended' objective function. ${ }^{7}$ In the former case, agents' utility function also depends in some way on the payoffs distribution among the group of people with whom the agent is interacting. This may lead to different specifications, such as aversion to inequality in surplus distribution, some form of altruism, or concern for one's own individual position within the payoffs ranking. In the latter case, agents are prompted to replicate the 'intention' perceived in others' actions, which builds on Rabin's seminal model of fairness (1993). ${ }^{8}$ Other models germane to this approach are those developed by Bernheim (1994) and Sugden ((1998) and (2000)) in the so-called normative expectations theories. The other-regarding motive is here associated with the desire to live up to others' expectations, so that the desire to obtain commendation and avoid disapproval by others about one's own actions is added to the self-interested motivation.

The model we develop in this paper generalises on these approaches in that it incorporates both types of other-regarding motivations, i.e. the social preference and the intention-based ones, into individual choice. The former type of motives is depicted as a shared moral principle on which agents form their moral or ideological assessment of the social outcomes. In section 3.2, we shape this as a contractarian moral principle, which takes on the specific functional form of the Nash social welfare function. The latter aspect enters the picture when we assume that agents' willingness to comply with moral prescriptions is conditional on their expectation of similar compliance by other agents. We model this feature by assuming that the expected conformity of other members of the community acts as an incentive to individual conformity, where purely altruistic and purely selfish behaviour can be seen as extreme cases of the model. We call this kind of motivation conformist preference. Both types of motivation add to a standard self-interested motivation within a comprehensive utility function.

A more extensive treatment of the formal properties of this model and its game theoretical underpinnings can be found in Grimalda and Sacconi (2002).

\subsection{Material and Ideal Utility}

\subsubsection{Consequentialist Preferences and the Material Game}

Preferences can be said to be consequentialist when they are defined in terms of the consequences of the agents' actions. Consider a situation of strategic interaction involving many agents. Each combination of individual actions generates a state of affairs that can be given a different description according to both the list of characteristics, and the list of individuals to which such characteristics are attributed, which are taken as relevant. In the case of consequentialist preferences, such a relevant list of characteristics only regards the consequences to the relevant set of individuals of the profile of individual actions. Such a list may for instance include an agent's wealth, leisure, effort, etc., and each agent may shape her own preferences so that only ber own characteristics are relevant, or she may include some other agents' - or even any other agent's - characteristics, too. At this point, though, we impose a first restriction on individual preferences, and we assume that the list of characteristics held as relevant by any player solely includes the consequences for her own self-interest of each actions profile, as is customary in

\footnotetext{
${ }^{7}$ Ben Ner and Puttermann (1998) provide a theoretical underpinning for such a model of individual choice by distinguishing among self-regarding, other-regarding and process-regarding motivations. See also Fehr and Schmidt (2001) for a review.

${ }^{8}$ For different models in which social preferences and intention-based reciprocity aspects are combined, see Charness and Rabin (1999), and Falk and Fischbacher (1999).
} 
many multiple motivations models (see section 2.1). An additional type of preferences will be illustrated in the next section.

These considerations may be given a formal representation in game theoretical terms as follows. First, we define the set $I$ of 'players' involved in the interaction. Second, each player $i \in I$ is characterised by a set of actions $\Sigma_{i}$, which lists all of the possible actions that the agent may perform within the interaction. $\sigma_{i}$ denotes the generic element of $\Sigma_{i}$. Moreover, $\sigma$ denotes a profile of actions for all players involved in the interaction. That is, $\sigma=\left(\sigma_{1}, \ldots . \sigma_{i}, \ldots, \sigma_{n}\right)$ is a list of actions for the $n$ players of the game. We can then define $\Sigma=\underset{i \in I}{\times} \Sigma_{i}$ as the whole set of individual actions profiles, and $\Sigma_{-i}=\underset{j \neq i}{\times \Sigma_{j}}$ the profile of actions played by $i$ s counterparts. In other words, the actions profile $\sigma \in \Sigma$ can be broken down into the pair $\left(\sigma_{i}, \sigma_{-i}\right)$, where the former element represents $i$ s own action, and the latter $\sigma_{-i} \in \Sigma_{-i}$ the actions profile of all of the other players except $i$. Each of these actions profile $\sigma$ is uniquely associated with a particular state of affairs, which the agent will describe in terms of the characteristics and set of individuals that she holds as relevant. That is, there exists a one-to-one correspondence between a particular actions profile $\sigma$ and a state of affairs, to which different descriptions may be appended.

Finally, we define a utility function $U_{i}(\sigma)$ for each agent involved in the interaction. Such a function expresses the extent to which the state of affairs brought about by the profile of actions $\sigma$ fulfils player is preferences over the consequences associated with $\sigma$. Since it has been assumed that only self-interest matters in consequentialist preferences, $U_{i}(\sigma)$ assigns a numerical value to each possible state of affairs, according to the greater or lesser fulfilment of player $i$ s self-interest. To contrast with an additional source of utility, we shall call $U_{i}(\sigma)$ material utility. Finally, $U=\underset{i \in I}{\times} U_{i}$ defines the set of individual utility functions. On the basis of this formal framework, we define the material game $G$ the triplet of elements: $G=\{I, \Sigma, U\}$.

\subsubsection{Conformist Preferences and Ideal Game}

In addition to the self-interested preferences and material utility, we assume that agents have a second general motivation, which this time pertains to the moral or ideological sphere. We call such preferences conformist, and we set a deontological element as their basis - i.e. agents are motivated to act by the awareness that their pattern of actions satisfies as such some formal properties, not by the value of outcomes of their actions. For instance, agents may attach value to the awareness that the decision procedure they follow is 'fair' according to some definition, or that their acts respect 'rights' or allocate benefits according to some rule that they deem 'just' or which is simply such that they accept it as a source of obligation. This can be construed in preference terms starting again from the description of states. ${ }^{9}$ Like the first type of preferences, conformist preferences are defined over states of affairs, but these latter are no longer described in terms of the consequences occurring to any individual. States of affairs are now primarily described as sets of interdependent actions (vectors of acts) to which each player's beliefs about the others' actions are appended. These are considered with respect to their coherence (or lack of coherence) with a given abstract principle of justice. Under this description, states are modes of joint behaviour by the players. We can identify a profile of actions as perfectly deontological when it fully complies with an abstract principle of justice or with a fair criterion of benefits distribution

${ }^{9}$ For a discussion of the properties of the descriptions of states of affairs, and for a substantial rejection of the view that these may be made so inclusive as to include deontological aspects as well as consequences, see Scanlon's (2001), and Verbeek (2001). However, see also Sen's (2001) reply. 
among the parties concerned. We may call this state the ideal. Then we can look for the degree of compliance with the ideal displayed by each state of affairs resulting from the individual choices actually made by all the players. This degree of compliance with the principle displayed by all the participants in the interaction is called 'joint conformity', and we take it to be the basic notion of value underlying conformist preferences. Contrary to a simplistic understanding of deontological reasoning, this means that the value underlying conformist preference is not mere individual compliance with a principle in isolation. We assume, on the contrary, that fulfilment of the moral principle depends on the joint pattern of actions carried out by all the agents involved in the interaction. Therefore, the less distance there is between a state of affairs and the ideal, the more this it is said to fulfil the normative principle and the higher the motivational strength to act in accordance to the principle itself for each player.

In this section such a principle of justice is presented as a wide-ranging normative criterion that consents an assessment of the states of affairs on the grounds of the extent to which a certain state of affairs may be gauged as 'just'. This will lead to the specification of a contractarian ideology in the NPO case in section 3.2. In the present section we shall refer to it interchangeably as an abstract principle of justice, a normative criterion, or as an ideology.

In formal terms, the change in the perspective from which the interaction is evaluated calls for the definition of a game different from the material game, which we call the ideal game. Firstly, agents may now include in the relevant description of the state of affairs other agents who are affected by their actions but cannot affect the final outcome. Hence, we call the ideal game $G^{*}$ an extension of the material game $G$ in which the set of players is possibly larger than in the material game and thus modifies the corresponding set of utilities. Formally, this game is defined by the triplet: $G^{*}=\left\{I^{*}, \Sigma, U^{*}\right\}$, with $I \subseteq I^{*}$ and $U^{*}=\underset{i \in I^{*}}{\times} U_{i}$. Note that the set of actions $\Sigma$ is left unaltered with respect to the material game: by definition the players now included in the game are dummy players in the original one.

On the basis of this construction, we can now introduce a formal representation of the abstract principle of justice that is used to appraise social states of affairs. This will measure the degree of conformity of agents' actions with the abstract principle of justice. In formal terms, this is given by a function $T(\sigma):=\Sigma \rightarrow R$, which supplies the agents with a metrics over the actions profile, and thus on each states of affairs, on the grounds of the moral principle shared by the agents. The function is defined on $\sigma \in \Sigma$, as there is a one-to-one correspondence between action profiles and states of affairs (see section 2.1.2). Note that the same states of affairs that received a certain description to generate consequentialist self-regarding preferences, are now described in a different manner in accordance with characteristics that are relevant for the abstract principle of justice. Thus, this normative principle permits an ordering of the possible states of affairs that represents the assessment that an impartial spectator would give to the different social situations on the basis of the relevant normative criterion of distribution. Note that it is assumed that this function is shared by all of the agents who are part of the interaction. This is formally equivalent to a social welfare function, in that the possible states of affairs are assigned a numerical value on the basis of the fulfilment of the abstract principle of justice that is shared by the agents ${ }^{10}$. In particular, the set of actions maximising such a function defines what we have referred to as the ideal state of affairs. Formally, this is indicated as an actions profile $\sigma^{*}=\underset{\sigma \in \Sigma}{\arg \max } T(\sigma)$. It is also

\footnotetext{
10 This specification is analogous to what Broome (1999) calls a betterness relationship. This is meant to introduce a binary relation on states of affairs on the grounds of whether there is more or less 'good' which permits to conclude that one state is 'better' than another. In spite of not corresponding to the typical 'desire' or 'revealed' interpretation of preferences, this ordering can be represented by a utility function.
} 
intended that the higher the value of the function $T$, the closer the state of affair to the realisation of the ideal.

\subsection{Mutual Conformity}

\subsubsection{A General Account of a Comprehensive Utility Function}

We now provide a formal specification of the comprehensive utility function, whose components are given by material and ideal utility. The first is given by the usual self-interested motivation, whereas the second hinges upon the ordering of the social outcomes performed by means of the normative principle $T$ introduced in the previous section.

The most general form that a comprehensive utility function may take is as follows:

$$
V_{i}(\sigma)=U_{i}(\sigma)+\lambda_{i} f[T(\sigma)] \quad i \in I^{*}
$$

The first term $U_{i}$ represents the material utility and is shaped in accordance with the agent's self-interested consequentialist preferences (section 2.2.1). The second term is the ideal utility and reflects the agent's concern with the conformity of the state of affairs with the principle of justice embodied in the function $T$. The relative weight attached to the ideal vis-à-vis the material source of utility is represented by the parameter $\lambda_{i}$, which may differ for the agents. For simplicity, the two components enter the function additively. The presence of a function $f$, common to all agents, which 'transforms' the social normative criterion into individual ideal utility, captures the idea that there may be different ways in which such a normative criterion enters individual ideal utility. The aim of this section is to offer a characterisation of the way players internalise this normative principle, which will be based on the idea of expected reciprocity in conforming with the normative prescriptions. More precisely, we have already stressed in section 2.2.2 the importance of joint conformity in the deontological reasoning. In this section we argue that ideal utility is shaped in accordance with two other specific properties, i.e. conditionality and reciprocity.

\subsubsection{Conditionality}

Although the fulfilment of a principle is understood in terms of the whole set of agents' actions, this does not preclude that an agent may assess the degree of fulfilment uniquely from its own perspective, conditionally on the expected actions performed by the other agents. In other words, provided that a metrics over states of affairs is shared among agents measuring the degree of fulfilment of the moral principle, an individual may ask herself whether or not her own action helps to get closer to the ideal, given the pattern of actions expected from other agents. Therefore, while we can define an absolute idea of fulfilment of the moral principle, when this is defined according to the joint set of actions performed by every agent, we are also enabled to define a conditional notion of fulfilment of the moral principle. In fact, we assume that individual conformist preferences reflect how each individual choice by the agent helps to generate a state of affairs as near to the ideal as possible, given (an expectation over) the other players' choices. Thus conditional conformity is what is properly involved in conformist personal preferences defined on the action set of each player.

We model these ideas by building on Rabin's model of fairness (1993). In analogy with his pair of kindness functions measuring the mutual impact of one's actions on others' individual utility, we introduce functions computing the degree of conformity with the ideal state of affairs, conditional on others' actions. We first define is conformity with morality as follows:

$$
f_{i}\left(\sigma_{i}\right)=\frac{T\left(\sigma_{i}\right)-T^{M A X}\left(\sigma_{i}\right)}{T^{M A X}\left(\sigma_{i}\right)-T^{M I N}\left(\sigma_{i}\right)}
$$


$T\left(\sigma_{i}\right)$ indicates the value of the normative criterion corresponding to $i$ 's actual choice $\sigma_{i}$, given her expectations on other players' actions. In both (2) and (3) below, the notation emphasises the set of agents who is considered to be 'acting' and then affecting the normative function score. This is why the term $\sigma_{-i}$ has in (2) been omitted from the arguments of the function $T$. $T^{M A X}\left(\sigma_{i}\right)$ and $T^{M I N}\left(\sigma_{i}\right)$ are the value assumed by the normative criterion in correspondence to player is actions that, conditional on the expectations on others' behaviour, comply to the maximum and minimum degree with the principle of justice incorporated in $T^{11}$. Therefore, if $T^{M A X}\left(\sigma_{i}\right)\left(T^{M I N}\left(\sigma_{i}\right)\right)$ obtains, then agent $i$ is maximising (minimising) the normative criterion given her expectation on others' actions. Therefore, $T^{M A X}\left(\sigma_{i}\right)$ is associated with agent $i$ performing the conditionally ideal action.

Therefore, $f_{i}\left(\sigma_{i}\right)$ is an index varying between -1 and 0 that is equal to $0(-1)$ when $i$ is exactly performing the action maximising (minimising) the moral/ideological prescriptions; that is, $i \mathrm{~s}$ action is consistent with the normative prescriptions to the maximum (minimum) degree. In other words, conformity with the agreed normative principle is measured by the extent to which an agent's action reduces the distance between the actual state of affairs and the conditionally ideal one, which is the state where the value of the normative function is maximised over the agent's strategy set given the expected choice by the counterparts.

\subsubsection{Reciprocity}

Our main assumption as regards how players come to attach value to individual conditional conformity with the moral principle is that this is mediated through expectations over the reciprocal degree of conditional conformity by the other agents. That is, the conditional willingness to comply depends on the (expected) compliance of other agents with the same moral principle. More precisely, we model mutuality by assuming that the closer the (expected) compliance of other members with morality, the greater the motivational force for the agent to comply with it as well.

The role played by reciprocity in individual compliance with the prescriptions of the principle of justice in determining the kind of preference we are defining is a strong reason for calling them conformist, because when a common pattern of behaviour abiding with the principle of justice has become established and is mutually expected among the players, then individual preferences, according to our view, reflect a willingness to conform with a generally accepted pattern of behaviour. The type of conformism we are describing is nonetheless moral, in that the principle whose general observance triggers utility is, in our model, the result of an ex-ante unanimous and impartial rational choice. ${ }^{12}$

To model the concept of reciprocity in the individual motivational system, we need to introduce a function symmetric to that set out in the foregoing section. This is the esteem accorded by player $i$ to other players' compliance with the ideology:

$$
\tilde{f}_{-i}\left(\sigma_{-i}\right)=\frac{T\left(\sigma_{-i}\right)-T^{M A X}\left(\sigma_{-i}\right)}{T^{M A X}\left(\sigma_{-i}\right)-T^{M I N}\left(\sigma_{-i}\right)}
$$

\footnotetext{
${ }^{11}$ More formally, $T^{M A X}\left(\sigma_{i}, \widetilde{\sigma}_{-i}\right)=\underset{\Sigma_{i}}{\arg \max } T\left(\sigma_{i}, \widetilde{\sigma}_{-i}\right)$ and $T^{M I N}\left(\sigma_{i}\right)=\underset{\Sigma_{i}}{\arg \min } T\left(\sigma_{i}, \widetilde{\sigma}_{-i}\right)$. Here $\widetilde{\sigma}_{-i}$ denotes $i$ 's expectation over other players' actions.

${ }^{12}$ For a different account of conformity, where there is no independent normative condition shaping the rule with which agents are required to conform, see Sugden (2000).
} 
Given this standpoint, $T^{M A X}\left(\sigma_{-i}\right)$ and $T^{M I N}\left(\sigma_{-i}\right)$ are the values that the normative criterion assumes when others players respectively maximises or minimises it, given player $i$ 's expectations ${ }^{13}$. In other words, these functions indicate the maximum and minimum values that other players can attribute to the normative criterion, given what $i$ perceives to be their expectations on her own behaviour. Once these are compared with $T\left(\sigma_{-i}\right)$, which is the actual value that $i$ expects the normative criterion to take according to her beliefs, the estimated compliance of other players with the normative principle that is expected by $i$ obtains.

Consequently, $\tilde{f}_{-i}\left(\sigma_{-i}\right)$ is an index of the expected conformity by other players with the normative criterion embodied in T. The closer $\widetilde{f}_{-i}\left(\sigma_{-i}\right)$ to $0(-1)$, the higher (lower) the degree of fulfilment of the principle of justice by other players, according to $i$ s expectations.

\subsubsection{The Comprehensive Utility Function}

The main elements of the construction developed in the previous sections are: (a) a standard game where payoffs represent the individual self-interests of the agents involved; (b) a normative function $T$ that expresses the ranking of the states of affairs based on the degree of fulfilment of a moral or ideological principle which is shared by the agents; and (c) a pair of functions depicting an agent's own degree of compliance with the ideological principle and the estimated degree of compliance by the other parties. Both functions (2) and (3) depend on the expectations that each agent forms about the other's behaviour.

We can now introduce the final version of the utility functions:

$$
\left.V_{i}(\sigma)=U_{i}(\sigma)+\lambda_{i}\left[1+\widetilde{f}_{-i}\left(\sigma_{-i}\right)\right] 1+f_{i}\left(\sigma_{i}\right)\right]
$$

Ideal utility consists of the product of the two conformity functions (2) and (3) each augmented by 1 . Conditionality is characterised in (4) by the presence of the term $\left[1+f_{i}\left(\sigma_{i}\right)\right]$, which enables the agent to gauge her own degree of compliance with the ideology given others' actions. Reciprocity enters the specification in that other players' (estimated) conformity, as expressed by $\tilde{f}_{-i}\left(\sigma_{-i}\right)$, acts as the 'marginal incentive' for the subject to pursuing her ideal motivations Therefore, the ideal utility increases the more the counterparts' profile of actions is perceived as consistent with the ideology, thus eliciting a similar behaviour in the agent herself. In the extreme case in which $\tilde{f}_{-i}\left(\sigma_{-i}\right)$ is equal to -1 , which denotes the worst action that other players can perform in terms of the ideology, the coefficient of the ideological motive becomes equal to zero, thus leaving self-interest as the only relevant motive to action. Conversely, when $1+\widetilde{f}_{-i}\left(\sigma_{-i}\right)$ is positive and sufficiently 'large', then agent $i$ may agree to pursue an action contrary to her selfinterest but that conforms with the normative principle.

\section{The Production Game}

Having set out the philosophical and analytical underpinnings of the agents' motivational system, we can now apply this decision-making model to the analysis of the NPO. We first depict a situation of interaction to produce a good (section 2.1) whose outcomes correspond to a variety

13 In formal terms, $T^{M A X}\left(\widetilde{\widetilde{\sigma}}_{i}, \sigma_{-i}\right)=\underset{\Sigma_{-i}}{\operatorname{argmax}} T\left(\widetilde{\widetilde{\sigma}}_{i}, \sigma_{-i}\right)$ and $T^{M I N}\left(\widetilde{\widetilde{\sigma}}_{i}, \sigma_{-i}\right)=\underset{\Sigma_{-i}}{\arg \min } T\left(\widetilde{\widetilde{\sigma}}_{i}, \sigma_{-i}\right)$. Note that when players assess others' compliance, she has to take into account of what action she expects others expect from her. This leads to the introduction of second order beliefs in this computation, which have been denoted with $\widetilde{\widetilde{\sigma}}_{i}$. 
of different organisational forms for a firm. This game is analysed in accordance with the two attitudes that make up the utility functions of the players. In section 3.2 the Nash social welfare function is adopted as the normative principle used by the agents. In section 4 we analyse the conditions under which a NPO can be an equilibrium of the game.

\subsection{The Setting of the Game}

We suppose that three players are involved in the production game: a worker (W), an entrepreneur $(\mathrm{E})$ and a consumer $(\mathrm{C}) .{ }^{14}$ The latter is in fact a dummy player, in that her actions have no impact on the others' payoffs, though her own payoff is affected by others' actions. The worker and the entrepreneur work together in a firm and have to decide the degree of their commitment to it, commitment that is assumed to be measurable along some scale. Their different degrees of involvement give rise to different organisational forms for the firm. More specifically, each of the active agents has two actions available: one is to be on a par with a preexisting free-market profit-oriented standard; the other, instead, permits some improvement in the quality of the supplied good with respect to such a standard, but triggers an extra cost that has to be borne by the agents themselves. For instance, the entrepreneur may decide to adopt a productive practice, or a technology, which increases the quality of the good but is more costly than the technology adopted in a purely competitive context. Analogously, the entrepreneur may forgo a part -or all - of his profits in order to reinvest them in the productive process either by improving the quality or increasing the quantity of the good supplied at the same price. We shall use $h_{E}$ and $l_{E}$ to denote adoption of the good's quality-improving action and the action which leaves the quality of the good unaltered with respect to the market standard respectively, where the letters $b$ and $l$ denote the high or low quality-enhancing purpose of the action, and the subscript $E$ stands for the entrepreneur.

Likewise, the worker may decide to work at a lower wage than that fixed in a free market context, thus partially - or totally - supplying his labour in a voluntary form. Similarly, he may increase his effort to furnish the good at the same wage. In both cases, either the quality of the good is improved or it is offered in a larger amount at the same price. We shall indicate this pair of actions with $h_{W}$ and $l_{W}$. The consumer does not undertake actions affecting the utility of the other two agents, but the surplus derived from the consumption of the good depends on its quality, and therefore on the level of effort made by the producers.

Drawing on the formalisation introduced in section 2, we distinguish between the set $I=\{W, E\}$ of the active players and the set $I^{*}=\{W, E, C\}$ that includes the dummy player $C$. A strategy set for the two agents can be easily introduced by considering that both perform an action that improves the quality of the good and another that leaves it unaltered with respect to a competitive context. Hence, $\Sigma_{i}=\left\{h_{i}, l_{i}\right\}, i \in I$.

The game representing the interaction depicted so far is as follows:

\begin{tabular}{|c|c|c|}
\hline & $b_{E}$ & $l_{E}$ \\
\hline$h_{W}$ & $\underline{w}, R-\underline{w}-c, s$ & $\underline{w}, R-\underline{w}, \delta s$ \\
\hline$l_{W}$ & $\bar{w}, R-\bar{w}-c, \delta s$ & $w, R-w, 0$ \\
\hline
\end{tabular}

Figure 1

14 As customary, we attribute different genders to the players. In particular, E and C are both females, whereas $\mathrm{W}$ is a male. 
where the following restrictions apply:

$$
\begin{aligned}
& \bar{w}>\underline{w} \\
& R-\underline{w}-c \geq 0 \\
& 0<\delta<1
\end{aligned}
$$

The first, second and third terms in each box represent the material payoffs for the worker, the entrepreneur and the consumer respectively. $c$ stands for the extra cost that must be paid by the entrepreneur if she wants to engage in the quality enhancing action of the good, namely $h_{E}$. $R$ indicates the revenues from sale of the good, which are assumed to be constant in any possible outcome, and $w$ is the wage, which enters as a cost for the entrepreneur and as the only source of material utility for the worker. ${ }^{15}$ There are two possible levels of the wage: $\bar{w}$ is a comparatively high level that obtains when the worker supplies an amount of labour in accordance with the market standard (strategy $l_{W}$ ), whereas $\underline{w}$ is a lower level for the wage that the worker is willing to earn when engaged in the good's quality enhancing action (strategy $h_{W}$ ). Therefore, the difference between $\bar{w}$ and $\underline{w}$ is the cut in the real wage that the worker is willing to accept in order to improve the quality of the good.

The consumer's utility is given by the surplus gained in the four possible outcomes. This depends on the effort made by the other agents to improve the quality of the good. In particular, we normalise to 0 the level of surplus in the outcome where neither the worker nor the entrepreneur engage in the quality improving action, that is $\left(l_{W}, l_{E}\right)$. We then assume that when both agents agree to enhance the quality of the good, the surplus gained by the consumer is equal to $s$, whereas when only one of the two agents contributing to production provides such an activity the surplus is only equal to a fraction $\delta$ of $s$. Hence, the two inputs are complements in improving the quality of the good.

We identify the outcome in which both agents perform the quality improving actions as the constitution of an NPO. The intuition is quite simple: provided that by construction the outcome $\left(l_{W}, l_{E}\right)$ is associated with the level of effort supplied in a free market context, in $\left(h_{W}, h_{E}\right)$ the entrepreneur forgoes (part of) her profits in order to invest in a quality-enhancing technology, or simply in order to increase the quality or the quantity of the good, while the worker supplies a larger amount of effort or some voluntary labour. The surplus of the consumer is in this case as high as possible. This seems to satisfy some of the most relevant properties that characterise an NPO. The other pair of outcomes represent instead different situations: $\left(h_{W}, l_{E}\right)$ gives the best payoff for the entrepreneur, because she can rely on the worker to make the maximum effort while not performing any quality-increasing action; conversely $\left(l_{W}, h_{E}\right)$ yields the worst payoff for the entrepreneur, because the extra costs that she sustains cannot be offset by the worker's provision of a certain amount of extra effort.

If the game were played by the two active players with no concern for the dummy player, then the game in fig.1 would degenerate into the following standard game, where only the agents' payoffs concerning their self-interest are considered, as only they are relevant to the solution of the game:

\footnotetext{
${ }^{15}$ For simplicity the material utility of both worker and entrepreneur is assumed to be linear in the monetary revenue.
} 


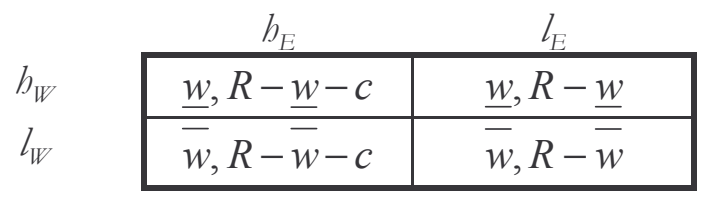

Figure 2

It is apparent that a unique Nash equilibrium in dominant strategies exists in which both agents perform the low-quality action. In fact, neither agent has an incentive to perform the qualityenhancing action, because the consumer's utility is neglected in this game. One may thereby state that an NPO can emerge only if an other-regarding attitude toward the beneficiary is sufficiently pronounced among the active agents. However, in what follows this attitude is not directly modelled as altruism toward the dummy player, but rather as a conformist preference for mutual compliance with an accepted principle of fairness or for the non-profit ideology. How this ideology comes to be selected is the topic of the next section.

\subsection{Contractarianism and the Ideology of the NPO}

The set of normative criteria moulding the conformist motive to action (see section 2) has not yet been specified. However, here we put forward a suggestion that we take to be reasonably appropriate to an account of the non-profit enterprise, both from the positive and normative standpoints, and which is based on the consideration that both the entrepreneur and the worker of the NPO are 'ideologues' (Ackerman (1996)). We make this point by introducing in sequence two assumptions meant to capture two distinct roles of morality in the NPO: the first is the 'rational justification giving' role, which we express in terms of contractarian ethics. The second is the motivational role, which we model under a particular interpretation of the ideal utility of the NPO members. It is a basic tenet of this paper that these two roles must be considered as indispensable yet irreducible to one another, so that both must be addressed directly by any endeavour to explain how morality can play a role in economic organisations. ${ }^{16 .}$

\section{Hp.1:The NPO internal players' ideology states that the NPO is based on a bypothetical 'social contract' among all the players - the consumer included - which affirms a principle of fairness.}

In this situation it is as if, before the players begin the actual game, all of them have already engaged in a hypothetical cooperative bargaining game (see section 2.2.2). This latter game captures the ex ante perspective according to which the players may agree to join the organisation in the different roles of entrepreneur, worker and consumer. In doing so, they seek a justification for their joining the organisation. They thus assume an impartial or moral stance whereby the decision to join must be rationally acceptable from whichever point of view. In other words, the terms of agreement must be rationally acceptable under the permutation of the personal or rolerelative point of views, so that the agreement is invariant when considered from the two apparently distinct perspectives: the perspective of each particular player, who chooses according to his best payoff, and the perspective of 'anyone' - that is, the perspective of whatever player who would consider the problem of finding an acceptable agreement without any knowledge of his name and personal role in the game. In other words, rationally agreed principles of fair distribution are what players would accept in an hypothetical bargaining situation among

16 For a similar point see Gauthier (1986), where he makes the basic distinction between internal rationality of the social contract, which can be solved in terms of rational bargaining theory, and external rationality of the social contact, i.e. the compliance problem, a point, however, that we address in a completely different way by introducing conformist preferences. 
symmetrically rational bargainers, all of whom are equally driven by rationality postulates derived from the same principle of utility maximisation under strategic interaction, but all of whom are equally unable to identify their own particular name and role in the game ${ }^{17}$.

In fact, the impartial perspective is adopted in order to settle the mission and the conjoint strategy of the organisation, by which is meant those that would be agreed to by all the NPO's internal members and its external stakeholders as well. This perspective is taken in order to identify the reasonable and acceptable balance among the claims of all participants from which the internal players derive the fiduciary duties that the NPO must discharge toward its beneficiaries (consumers). Thus the 'social contract' works as a 'constitutional' ideology legitimating the enterprise as an institution from the ex-ante perspective.

At the core of the contractarian approach lies the idea that a fair distribution can be achieved through a rational agreement reached by all the interested parties to their mutual advantage. The inclusion of the consumer within the set of bargaining players is due to the impartial perspective taken in this justificatory exercise. Because it is an example of the justificatory role of ethics, it disregards the effective influence of the dummy players in the actual game. Instead, it considers the ex ante perspective in which also the consumer has a voice in the terms of agreement on the cooperative venture to which the beneficiary essentially contributes because she agrees to consume the organisation's output. A rational agreement in this hypothetical game thus requires the efficient production of the surplus and its fair distribution among both the internal and external players.

Formally, this can be modelled as the requirement that the NPO must distribute the surplus according to the Nash bargaining solution for cooperative bargaining games, i.e. we pick up the distribution maximizing the product of the three players' payoffs net of the status quo. Note that the Nash bargaining solution always selects an outcome reflecting the degree of symmetry of the payoff space, which means that if the payoff space is symmetric the solution is perfectly symmetric among the players (i.e. it splits the pie into equal parts). Consequently the solution is covariant with any asymmetry in the utility representation of the outcome space. This solution excludes any discrimination against any player (of course the utilities' product becomes zero if any factor in the multiplication is zero) and always selects equality in so far as equality is represented in the shape of the payoff space. In sum, we adopt the Nash bargaining solution as a normative criterion for defining a moral preference regarding the outcomes of the original game, which orders outcomes according to 'fairness. ${ }^{18}$

With respect to the non-cooperative game discussed in the previous section, the constitutional ideology is what can be called the result of a 'pre-play communication' phase, an agreement that players reach before beginning the actual non-cooperative game on surplus allocation. However the actual game in the previous section is non-cooperative. Which means that commitments on the ideological principle are not binding per se, and there is nothing in the rules of the game to ensure that the precepts of the ideology will be enforced or put in practice by the players. Moreover, due to the payoffs structure of the actual game and its Nash equilibrium, we know that the players do not have the appropriate incentives to put the precepts of

17 Harsanyi (1977) and Gauthier (1986) offer two alternative statements of the set of symmetrical rationality postulates from which the bargaining solution is derived. Binmore (1997) shows a symmetrical bargaining game suitable for ethical theory. See also Sacconi (1991) for a different account.

18 The idea to base the social contract on Nash's bargaining solution was first put forward by Horace Brock (Brock 1979) see also (Sacconi (1991); (2000)). It is also adopted in a somewhat different way by Binmore (1997). Note that the use of the term 'social welfare function' does not imply the presence of some sort of super-individual decision maker whose objective function is defined according to the social welfare function. In that notion we are only interested in the aspect of ordering of state of affirairs according to a criterion of fairness. 
the constitutional ideology into practice. Why, then, do the active players, the entrepreneur and the worker, comply with their constitutional ideology? A reply is provided by our second hypothesis.

\section{Hp 2.The internal NPO players take the expectations of reciprocity in conformity with the constitutional} ideology to be a source of utility per se.

In other words, there is an intrinsic source of utility accruing to action in accordance with the ideology in the event that a player believes that, whilst acting in accordance with the ideology, the other players are also complying with the same ideology, and the player also believes that the others in fact expect that she is acting in accordance with the ideology whilst they are doing so. This is where ideal utility based on conformist preferences enters the production game; but now the resulting comprehensive utility function of the players is specified by the contractarian form of the NPO members' ideology.

On the grounds of the above discussion, we take the Nash social welfare function to represent the normative criterion to assess state of affairs that was introduced in its general form in expression (1). The Nash social welfare function reads as follows:

$$
N\left(U_{1}, \ldots U_{N}\right)=\prod_{i=1}^{N}\left(U_{i}-d_{i}\right)
$$

where $d_{i}$ represents the reservation utility that agents can obtain when the bargaining process breaks down: that is, when they relinquish mutual cooperation. In the present context, we deem it appropriate to set all these reservation utilities to zero. ${ }^{19}$

Applying this function to our model, and expressing it with respect to the pair of the relevant agents' actions, we obtain the following values:

$$
\begin{aligned}
& N_{h h} \equiv N\left(h_{W}, h_{E}\right)=\underline{w}(R-\underline{w}-c) s \\
& N_{h l} \equiv N\left(h_{W}, l_{E}\right)=\underline{w}(R-\underline{w}) \delta s \\
& N_{l h} \equiv N\left(l_{W}, h_{E}\right)=\bar{w}(R-\bar{w}-c) \delta s \\
& N_{l l} \equiv N\left(l_{W}, l_{E}\right)=0
\end{aligned}
$$

For a significant set of the parameters, we can assume that the Nash function is maximised in $\left(b_{W}, h_{E}\right)$, which, according to the discussion in section 3.1, would so become the allocation obtained from bargaining among the three agents. In particular, for this to be the case it is required that:

$$
\begin{aligned}
& N_{h h}>N_{h l} \Leftrightarrow R-\underline{w}>\frac{c}{1-\delta} \\
& N_{h h}>N_{l h} \Leftrightarrow \frac{R-\underline{\underline{w}}-c}{R-\overline{\bar{w}}-c}>\delta \frac{\bar{w}}{\underline{w}}
\end{aligned}
$$

Condition (8) implies that the extra cost required for the quality improving technology, weighted by the consumer's surplus gain, be not too large in comparison with the profits of the firm when

19 This choice calls for some justification. Many authors would argue that the proper choice for the 'exit option' would be the Nash solution of the material game played non-cooperatively. However, this choice is not immune from criticism, because a possible situation of prevarication by one party toward the other in the status quo would carry over to the final 'moral' solution. This is the reason why other authors have proposed the notion of a 'moralised' status quo, in which some minimal form of reciprocal respect is already in place. Therefore, our choice may be considered equivalent to a, perhaps naive, notion of moralisation of the status quo from which the 'bargaining' starts. 
the worker accepts the lower wage. Condition (9) ensures that the increase in the consumer and entrepreneur's utility when the worker supplies the higher effort compensates the worker's loss of utility.

It is noteworthy that the lower $\delta$, the higher the range of parameters for which these conditions are satisfied. That is, the higher the consumer's surplus gain when both agents, rather than only one, supply their higher possible effort, the more likely the outcome associated with the $\mathrm{NPO}$ constitution be seen as the ideal from the contractarian point of view. This observation also bears important implications as regards the type of goods that the NPO is more likely to provide. According to this model, the NPO will establish in those sectors where the joint effort of the participants in the productive activity brings about a higher surplus to the consumer. In other words, a large enough gain in consumer's surplus vis-à-vis a loss in either entrepreneur or worker's utility is necessary in order to make the NPO outcome the optimal allocation in terms of the contractarian criterion. This simple observation can perhaps offer some insight into why not-forprofit organisations can be most likely observed in sectors such as health and education, rather than in, say, the production of manufactured goods. For it may be argued that it is indeed in the former sectors that an increase in the quality of the good triggers a higher surplus gain for the consumer than in manufactured goods. The reason lies in that these goods are directly related to the well-being of an individual, thus the quality improvement of the good directly contributes to her welfare. Conversely, in the case of a generic manufactured good, the increase in the quality typically causes an improvement in some characteristics that are most of the times only ancillary to the main function of the commodity. For instance, a streamlined car may certainly offer better performances and be more eye-catching than a more basic model, but it is doubtful that the former can trigger an improvement in the consumer's well-being ${ }^{20}$ able to elicit the dispositions of morality-oriented individuals to forego part of their material gains and benefit a third party. On the contrary, a quality improvement in the services provided to a person's health and education, benefits more directly the individual well-being, thus appearing more likely to prompt other-regarding individuals to set up productive activities enhancing consumers' surplus.

\section{THE EQUILIBRIA OF THE GAME}

\subsection{The NPO Psychological Nash Equilibrium}

The innovation introduced in the comprehensive utility function, that is, the interdependence of the utility functions and the inclusion of beliefs in its arguments, calls for an extension of the standard concept of a solution to games, namely the Nash equilibrium. We shall adopt the original notion of Nash psychological equilibrium put forward by Geanakoplos et al. (1989). The idea underlying this concept is that, if equilibrium obtains, then the expectations of rational players must be coherent with the actions being played, that is, they must be grounded on the knowledge that the equilibrium action profile will be played with certainty. In Grimalda and Sacconi (2002) we develop this argument formally. This condition of coherence of beliefs adds to the standard one that the profile of actions maximises individuals' comprehensive utility function, so that the psychological Nash equilibrium notion appears as a generalisation of the standard Nash equilibrium.

\footnotetext{
${ }^{20}$ Note that here we are referring to an 'objective' notion of well-being, rather than a subjective one. It is apparent that a consumer may be willing to spend high amount of money for an improvement that only marginally affects her own well-being, but it is obvious that it is the former notion that ideologicallydisposed individuals will take into account.
} 
It can now be straightforwardly shown how agents having preferences as expressed in (4), who use the Nash social welfare function as the normative criterion, view this outcome as optimal when the conformist utility is sufficiently high with respect to the material utility. Specifically, we want to prove that $\left(h_{W}, h_{E}\right)$ can be sustained as a Nash psychological equilibrium. Let us first consider the position of the worker and compute his level of utility associated with such an outcome. His material utility is clearly given by the lower wage; but what about his conformist utility? Recalling the expressions of the functions (2) and (3) measuring conformity with the ideology, we may note that, provided $N_{b b}$ is the maximum for the function, both compliance functions will be equal to zero, thus attributing the maximum value possible to the ideal utility:

$$
V_{W}\left(h_{W}, b_{W}^{1}=h_{E}, b_{W}^{2}=h_{W}\right)=\underline{w}+\lambda(10)
$$

Note that, in spite of the ideology normative function (6) depending on all of the agents' utility, individual ideal utility solely depends on the worker's utility himself. This is a result of the fact that, according to the argument of section 2.3, compliance with the ideology gains relevance for the agents in deontological terms, rather than in consequentialist ones. As a result, what agents attach importance to is the degree of joint conformity from the group of agents, rather than the fulfilment of the principle per se. Note that in the computation of (10) we have used the requirement of coherence with the equilibrium strategy implied by the Nash psychological game equilibrium.

Let us now test whether the worker finds this allocation optimal or whether he has any incentive to deviate. In psychological games, a deviation from a certain allocation consists of a change in the agent's strategy, given the set of beliefs coherent with that allocation. In other words, when deviating from a certain outcome, the agent must take account that others' expectations are coherent with her performing the action leading to that outcome. She can then compute the possible change in her own comprehensive utility deriving from not conforming with such expectations. In our case, we shall generically indicate with $\sigma_{W}<1$ the probability with which the worker plays $h_{W}$ in the mixed strategy adopted in the deviation. The estimation of the entrepreneur's compliance with the ideology is unaffected by this deviation, since by construction the worker knows that she still believes that he is going to perform $h_{W}$. Hence, $\tilde{f}_{-W}\left(h_{E}\right)=0$.

However, the worker's conformity with the normative principle must change. Given that the entrepreneur is still going to perform $h_{E}$ with probability one, the resulting value for the Nash function is:

$$
N\left(\sigma_{W}, h_{E}\right)=\sigma_{W} N_{h h}+\left(1-\sigma_{W}\right) N_{l h}
$$

Given the worker's belief, his action that maximises (minimises) the Nash function is playing $h_{W}\left(l_{W}\right)$. Formally: $N^{M A X}\left(\sigma_{W}\right)=N_{h h}$, and $N^{M I N}\left(\sigma_{W}\right)=N_{l h}$. On substituting these values into the function measuring the worker's conformity with the ideology, we obtain:

$$
f_{W}\left(\sigma_{W E}\right)=\frac{\left(1-\sigma_{W}\right)\left(N_{l h}-N_{h h}\right)}{N_{h h}-N_{l h}}=-\left(1-\sigma_{W}\right)
$$

Hence, the comprehensive utility of the deviation is:

$$
V_{W}\left(\sigma_{W}, h_{E}\right)=\sigma_{W} \underline{w}+\left(1-\sigma_{W}\right) \bar{w}+\lambda \sigma_{W}
$$

Ideal utility is now smaller than in (10), as the worker is paying a 'psychological' cost for the fact that he is not reciprocating the action of the counterpart. Knowing that the entrepreneur is doing her best to act in accordance with the normative principle, the fact that he is partly failing to do the same causes lesser satisfaction to derive from the conformist motive. A different but related interpretation is that the worker feels guilty at not having conformed with the counterpart's expectations. On the other hand, the expected value from the material utility is 
certainly higher. To ensure the optimality of the choice of the quality improving action for the worker, we therefore need a further condition:

$$
V_{W}\left(h_{W}, h_{E}\right)>V_{W}\left(\sigma_{W}, h_{E}\right) \Leftrightarrow \lambda_{W}>\bar{w}-\underline{w}
$$

This condition states that the weight attributed to the ideal utility must be sufficiently large to compensate the loss in material utility caused by not performing the best action in terms of selfinterest.

An analogous condition ensuring pursuit of the quality improving action holds for the entrepreneur:

$$
V_{E}\left(h_{E}, h_{W}\right)>V_{E}\left(\sigma_{E}, h_{W}\right) \Leftrightarrow \lambda_{E}>c
$$

We therefore have a simple intuition of how the presence of a conformist motivation in the individual system of preferences helps the emergence of an equilibrium associated with what we can identify as the NPO. When the importance attributed to this is sufficiently high compared with the material gain that must be forgone when acting in conformity with the normative principle, then the outcome in which both agents perform their best action in terms of the interests of the third party involved in the interaction, acting contrarily to what the pursuit of their mere self interest would prescribe, emerges as an equilibrium of the game. Hence, the presence of two agents motivated to act in accordance with the normative principle, which we identify with the NPO constitutional ideology, emerges as a necessary condition for the emergence of an equilibrium where we observe the typical behaviour of the NPO.

Thus far this result seems fairly natural: whenever two agents are sufficiently concerned to conform with the normative criterion, and when they entertain reciprocal expectations that both will abide by such a criterion, then a conformist equilibrium emerges as a solution of the game. However, there are some questions still unanswered: is the presence of ideology-'motivated' agents a sufficient condition for the emergence of this outcome? As we shall argue in the next section, the answer is in fact negative: even when the agents have conformist preferences, the type of interaction resembles a coordination problem where the outcome corresponding to the FPO can emerge as an equilibrium as well.

\subsection{Multiple Equilibria in Organisational Settings}

Let us examine whether the opposite outcome to that considered thus far, the one in which both agents perform the best action in terms of their self-interest $\left(l_{W}, l_{E}\right)$, can be sustained as a psychological equilibrium. The answer is in fact that it can. Consider the worker's situation. Since each agent is performing the worst action in terms of maximisation of the normative function given the belief about the others' action, the worker derives utility only from the material component:

$$
V_{W}\left(l_{W}, l_{E}\right)=\bar{w}
$$

However, the worker cannot gain any benefit from the deviation from this outcome: in fact, the esteem accorded to his counterpart is at the minimum level, namely:

$$
\widetilde{f}_{E}\left(b_{W}^{1}=l_{E}, b_{W}^{2}=l_{W}\right)=-1
$$

Therefore, he has no incentive to perform an action contrary to his self-interest and somehow respecting the moral principle. Every other strategy cannot but be worse than the current outcome.

Obviously, similar considerations hold for the entrepreneur, so that $\left(l_{W}, l_{E}\right)$ becomes a psychological Nash equilibrium for the game. This is indeed a relevant fact: even when agents are inclined to act in accordance with the moral principles accepted by the players - that is, their $\lambda_{s}$ are sufficiently high and this is known to them - there exists an equilibrium where the agents are indifferent to such morality-grounded motivations and only perform the action that suits their 
self-interest. This may be seen as a sort of 'organisational failure': even when the conditions necessary for the creation of an NPO are in place, the self-interest-based form of organisation may nonetheless emerge. Note that the NPO would be the best outcome for conformity-inclined agents; the FPO equilibrium is in this case Pareto-dominated by the other. In other words, the situation is similar to a co-ordination problem where the existence of a multiplicity of equilibria leaves unresolved the problem of selecting one of these two forms of productive organisation. That this is indeed the case can be shown more generally: the problem of the choice of each agent's best reply to that of the opponent is represented by the fig.3. It is evident that there is a threshold level in the best reply functions such that each agent performs the action complying with the contractarian ideology only if the counterpart's action complies at a is sufficiently high degree, and vice versa. This gives rise to a third equilibrium - this time in mixed strategies - for the game.

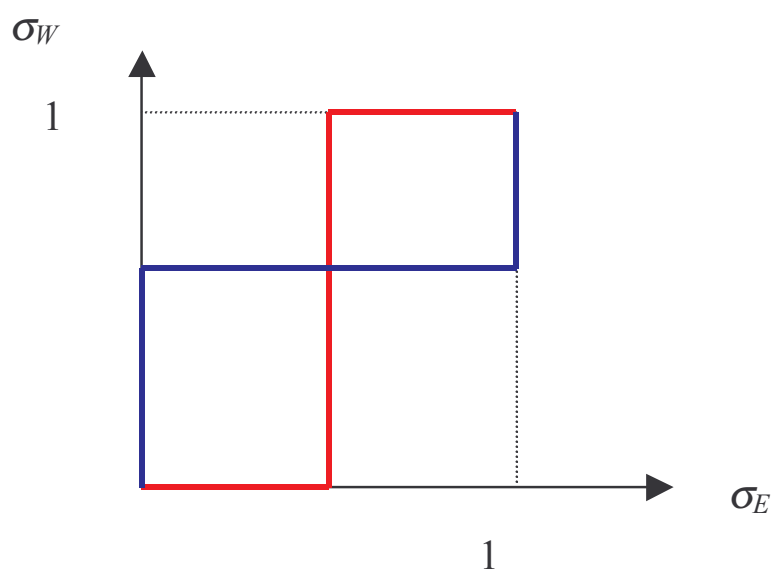

Figure 3

Therefore, the presence of a significant propensity by the agents to perform the actions prescribed by the fairness principle to their fullest extent is a necessary condition for the NPO to be derived as an equilibrium of the game, but it is not a sufficient one. Even when agents assign a large 'weight' to their conformist motive to action, failure to signal their attitude to their counterpart may lead to selection of the FPO as the equilibrium.

This observation points up the importance of some characteristics of the possible coordination equilibria that may be 'external' to the inner structure of the game, and which may act as focal points whereby one of the equilibria is 'salient' with respect to the others. As suggested extensively in the literature (Schelling (1960); Lewis (1969); Sugden (1986)), the ability to recognise the salience of one outcome within a set of available results rests on the sharing by the agents of cultural traits that makes convergence to that outcome common knowledge for all the agents. In the present context, it could be imagined that allowing communication in a pre-play stage of the game between the players may suffice to co-ordinate their expectations about the efficient outcome and solve the organisational failure. ${ }^{21}$ However, this simple device seems not to suffice in the more complex - and more realistic - case of incomplete information about each other's types by the players. This would be a situation in which the disposition of the agents as to their conformist attitude is a private hidden characteristic, namely a 'type'; so that each weight $\lambda_{i}$ would be a private characteristic unknown to the counterpart. It is clear that in such a situation even a cheap talk phase preceding the actual game would not help solve the co-ordination

\footnotetext{
${ }^{21}$ Sacconi $(2002 ; 2001)$ and Grimalda and Sacconi (2002) discuss the role of codes of ethics as devices to solve this type of co-ordination problem in situations of radical uncertainty.
} 
problem. For a profit-oriented entrepreneur - i.e. one with a low value for $\lambda i$ - might falsely announce that she has a high value of $\lambda i$ in order to induce non profit-oriented workers to collaborate with her. She could then 'exploit' the workers by paying them the lower wage without performing the quality-improving action. If there is asymmetric information concerning the quality of the good provided - that is, if workers are not able to assess its quality - then this situation may even become, to some extent, stable over time. The incentive for entrepreneurs with a low $\lambda$ to 'cheat' in the pre-play phase might then give rise to the well-known result of a pooling equilibrium in a signalling game. We therefore believe that the existence of multiple equilibria in the setting with complete information signals the presence of a key problem that persists in incomplete information settings.

\section{Conclusions}

The purpose of the paper has been to account for the NPO in terms of the motivation of the agents involved. Sections 2 has been devoted to developing a comprehensive model of individual motivations in which consequentialist and conformist preferences are combined into a coherent system of choice. The latter are shaped as a deontological motive to comply with a shared principle of justice conditionally on other individuals' compliance. In section 3 we have applied this model to the case of the NPO. We have built a simple 'production game' which is geared to describing a generic interaction between two constitutive members of a firm, such as an entrepreneur and a worker, who have to decide their degree of commitment to the firm. A third 'dummy' player stands to benefit of possibly higher quality of the good produced, were the firm to increase the quality of the good relative to the free-market standard. However, this requires 'active' players to forego part of their material gains.

In section 4 we have shown that the presence of conformist preferences is necessary for there to be an outcome different from conformity with the FPO. In particular, for an NPO equilibrium to obtain, first, agents must attach a sufficiently high weight to the conformist motive to action visà-vis the material loss experienced when complying with the moral prescriptions incorporated in the NPO ideology. Second, such an ideology that agents incorporate into their system of ends is contractarian in character and is the result of a - possibly hypothetical - social contract between the relevant figures participating in the venture and their stakeholders. In particular, ideology is inclusive in that not only does it take account of the interests of the agents active in the productive enterprise, but also of the interests of other beneficiaries and stakeholders of the good produced, e.g. consumers of the good. By conforming with the ideology, therefore, the constitutive members give 'voice' to categories otherwise excluded from decisions concerning the allocations of goods.

We have also shown how the interaction is alike a co-ordination game, so that a problem of multiplicity of equilibria arises. In particular, an 'organisational failure' emerges when reciprocal expectations do not converge on the NPO outcome even when agents' dispositions are such that this would be their individually - as well as socially - most preferred outcome. We have discussed how this case is even more likely to occur in the more realistic setting of informational asymmetry on one another's 'type' by the firm's constitutive members. Finally, the characterisation of the NPO as the outcome that maximises the consumer's surplus, vis-à-vis other outcomes in which this is only partly - or not at all - increased with respect to the freemarket standard characteristic of the FPO, helps give a simple intuition about which industrial sectors the NPO is more likely to occupy. Such will be those sectors where the joint effort of the firm's constitutive members is more likely to increase the stakeholders' surplus.

We are aware that the model used in the paper is extremely simple and does not capture all the strategic and organisational issues associated with the NPO. In particular, whereas this paper has focussed on relations internal to an organisation, it has not considered the NPO external 
relations with donors and stakeholders different from consumers. However, such aspects as the role of the NPO's reputation in situations of repeated interaction may be accommodated within the current framework, as shown in Sacconi (2002), and would not change the basic idea emphasised in this paper as to the constitutive elements of the NPO. Another possible extension is the treatment of the more realistic setting in which the disposition of the agents as to their conformist attitude is a private hidden characteristic, namely a 'type'. This would bring in the aspect of the efficiency of NPOs with respect to FPOs.

However, we believe that a significant result in even this simple setting is the multiple equilibria that emerge from the interactions among individuals conditionally disposed to conform to the firm's constitutional ideology. This outcome underpins the view that the shift from the motivational level of individuals to that of the organisation as a whole is far from unidirectional. Therefore, we believe that this result highlights the importance of the line of inquiry pursued in the present paper.

\section{References:}

- Andreoni, J. and Miller, J. (1993). 'Rational Cooperation in the Finitely Repeated Prisoner's Dilemma: Experimental Evidence', Economic Journal, Vol. 103, pp. 570-585

- Anderson, P., Arrow, K. (Ed.), Pines, D., (Eds.), (1988). The economy as an evolving complex system: Proceedings of the Evolutionary Paths of the Global Economy Workshop, held in September 1987, in Santa Fe, Reading, Mass.; Wokingham: Addison-Wesley

- Ben Ner, A. and L. Putternam (eds.) (1998), Economics, Values, and Organization, Cambridge: Cambridge University Press, pp. 3-69.

- Bernheim, B. (1994): 'A Theory of Conformity', Journal of Political Economy, Vol. 102, N. 5, pp.841-877.

- Binmore, K., Gale, J. and Samuelson, L. (1995). 'Learning to be Imperfect: The Ultimatum Game', Games and Economic Behavior, Vol. 8, pp.56-90

- Binmore, K. (1997), Just Playing; Game theory and the social contract, vol.2, Cambridge MA: The MIT Press

- Binmore, K. (1994), Game Theory and the Social Contract Volume 1: Playing Fair, Cambridge MA: The MIT Press.

- Brennan, G. and Hamlin, A. (2002). 'Expressive Constitutionalism', Constitutional Political Economy, V. 13, pp. 299-311

- Brennan, G. and Lomasky, L. (1993). Democracy and Decision, Cambridge: Cambridge University Press

- Brock, H. (1979), 'A Game theoretical Account of social Justice', Theory and Decision, V. 11, pp.239-265.

- Broome, J. (1999), Ethics out of economics, Cambridge: Cambridge University Press.

- Buchanan, J. (1975), The Limits of Liberty, Chicago: Chicago University Press

- Buchanan, J. (1988), 'Contractarian Political Economy and Constitutional Interpretation', American Economic Review, Papers and Proceedings, V. 78, pp. 135-39

- Charness, G. and Rabin, M. (2000). 'Social Preferences: Some Simple Tests and a New Model', mimeo, University of California at Berkeley

- Croson, R. (1999). 'Theories of Altruism and Reciprocity: Evidence from Linear Public Good Games', Discussion Paper, Wharton School, University of Pennsylvania

- Dawes, R. M. and Thaler, R. (1988). 'Cooperation', Journal of Economic Perspectives, Vol. 2, pp. 187197

- Dawes, R., van de Kragt, A., and Orbell, J., (1988). 'Explaining Discussion Induced Cooperation', Journal of Personality and Social Psychology, 54, 811-819

- Falk, A. and Fischbacher, U. (1999): 'A Theory of Reciprocity', Institute for Empirical Research in Economics, University of Zurich, WP N. 6 
- Fehr, E. and Gachter, S. (2000). 'Cooperation and Punishment in Public Goods Experiment', American Economic Review, 90, 980-994

- Fehr, E. and Schmidt, K. (2001): 'Theories of Fairness and Reciprocity - Evidence and Economic Applications', Institute for Empirical Research in Economics, University of Zurich, WP N. 75

- Gauthier D. (1986), Morals by Agreement, Clarendon Press, Oxford.

- Geanakoplos, J., Pearce, D., and Stacchetti, E. (1989), 'Psychological Games and Sequential Rationality', Games and Economic Behavior, Vol. 1, pp. 60-79

- Grimalda, G. and Sacconi, L. (2002). 'The Constitution of The Non-profit Enterprise: Ideology, Reciprocity', LIUC Papers series, N. 105

- Guth, W., Kliemt, H., and Ockenfels, A. (1982). 'An Experimental Analysis of Ultimatum Bargaining', Journal of Economic Behavior and Organisation, Vol. 3, pp. 367-388

- Hansmann, H. (1988), 'Ownership of the firm', Journal of Law, Economics and Organisation

- Hansmann, H. (1980), 'The Role of Non-profit Enterprise', Yale Law Journal, Vol. 89, pp. 835901.

- Harsanyi, J. (1977), Rational Behavior and Bargaining Equilibrium in Games and Social Situations, Cambridge University Press.

- Kreps D.M (1990), 'Corporate Culture and Economic Theory', in J. Alt and K. Shepsle, (eds.), Perspectives inn Positive Political Economy, Cambridge U.P.

- Kreps, D., Milgrom, P., Roberts, J., and Wilson, R. (1982). 'Rational Cooperation in Finitely Repeated Prisoners' Dilemma', Journal of Economic Theory, 27, 245-252

- Lewis, David (1969): Convention: A Philosophical study, Cambridge, Massachusetts: Harvard University Press.

- Nelson, R. and S. Winter, (1982): An Evolutionary Theory of Economic Change, Cambridge MA: Harvard University Press

- Rabin, M. (1993): 'Incorporating Fairness into Game Theory', American Economic Review, Vol. 83, N. 5, pp. 1281-1302.

- Rose-Ackerman, S. (1996), 'Altruism, Non-profits, and Economic Theory', Journal of Economic Literature, Vol. 34, pp. 701-728.

- Rose Ackerman, S. (1987), 'Ideals Versus Dollars: Donors, Charity Managers, and Government Grants', Journal of Political Economy, Vol. 95 N. 4, pp. 810-823.

- Sacconi L. (2002); 'The efficiency of the non profit enterprise: constitutional ideology, conformist preferences and reputation', LIUC paper $n$. 111, July; forthcoming in B. Hogdson (ed.) The Invisible hand and the common good, proceedings of the SEEP Conference, Berlin: Springer Verlag.

- Sacconi (2001), Incomplete contracts and corporate ethics: a game theoretical model under furay information, Liuc Papers n.91 October.

- Sacconi (2000), The Social Contract of the Firm, Berlin: Springer.

- Sacconi, L. (1991), Etica degli affari, individui, imprese e mercati nella prospettiva dell'etica razionale, Milano: Il Saggiatore.

- Scanlon, T.M. (2001), 'Symposium on Amartya Sen's Philosophy: 3 Sen and Consequentialism', Economics and Philosophy, Vol. 17, pp. 39-50.

- Schelling, T. C. (1960) Strategy of Conflict, Cambridge, MA.: Harvard University Press.

- Sen, A (2001), 'Symposium on Amartya Sen's Philosophy: 4 Reply', Economics and Philosophy, Vol. 17, pp. 51-66.

- Sugden, R. (2000): The motivating power of expectations, in J. Nida-Rumelin and W. Spohn, (eds). Rationality, Rules and Structure, Amsterdam: Kluwer, pp. 103-29

- Sugden, R. (1998), 'Normative expectations: the simultaneous evolution of institutions and norms', in Ben-Ner, A. and Putterman, L. (eds): Economics, Values, and Organization, Cambridge: Cambridge University Press, pp. 73-100. 
- Sugden, R. (1986). The Economics of Welfare, Rights and Co-operation, Oxford: Basil Backwell

- Verbeek, B. (2001), 'Consequentialism, Rationality and the Relevant Description of Outcomes', Economics and Philosophy, V. 17, pp. 181 - 205.

- Weisbrod, B. (1988) The Non Profit Economy, Cambridge, MA: Harvard University Press. 


\section{Elenco dei papers del Dipartimento di Economia}

2000.1 A two-sector model of the effects of wage compression on unemployment and industry distribution of employment, by Luigi Bonatti

2000.2 From Kuwait to Kosovo: What have we learned? Reflections on globalization and peace, by Roberto Tamborini

2000.3 Metodo e valutazione in economia. Dall'apriorismo a Friedman, by Matteo Motterlini

2000.4 Under tertiarisation and unemployment. by Maurizio Pugno

2001.1 Growth and Monetary Rules in a Model with Competitive Labor Markets, by Luigi Bonatti.

2001.2 Profit Versus Non-Profit Firms in the Service Sector: an Analysis of the Employment and Welfare Implications, by Luigi Bonatti, Carlo Borzaga and Luigi Mittone.

2001.3 Statistical Economic Approach to Mixed Stock-Flows Dynamic Models in Macroeconomics, by Bernardo Maggi and Giuseppe Espa.

2001.4 The monetary transmission mechanism in Italy: The credit channel and a missing ring, by Riccardo Fiorentini and Roberto Tamborini.

2001.5 Vat evasion: an experimental approach, by Luigi Mittone

2001.6 Decomposability and Modularity of Economic Interactions, by Luigi Marengo, Corrado Pasquali and Marco Valente.

2001.7 Unbalanced Growth and Women's Homework, by Maurizio Pugno

2002.1 The Underground Economy and the Underdevelopment Trap, by Maria Rosaria Carillo and Maurizio Pugno.

2002.2 Interregional Income Redistribution and Convergence in a Model with Perfect Capital Mobility and Unionized Labor Markets, by Luigi Bonatti.

2002.3 Firms' bankruptcy and turnover in a macroeconomy, by Marco Bee, Giuseppe Espa and Roberto Tamborini.

2002.4 One "monetary giant" with many "fiscal dwarfs" : the efficiency of macroeconomic stabilization policies in the European Monetary Union, by Roberto Tamborini.

2002.5 The Boom that never was? Latin American Loans in London 1822-1825, by Giorgio Fodor.

2002.6

L'economia senza banditore di Axel Leijonhufvud: le 'forze oscure del tempo e dell'ignoranza' e la complessità del coordinamento, by Elisabetta De Antoni. 
2002.7

Why is Trade between the European Union and the Transition Economies Vertical?, by Hubert Gabrisch and Maria Luigia Segnana.

2003.1 The service paradox and endogenous economic gorwth, by Maurizio Pugno.

2003.2 Mappe di probabilità di sito archeologico: un passo avanti, di Giuseppe Espa, Roberto Benedetti, Anna De Meo e Salvatore Espa.

(Probability maps of archaeological site location: one step beyond, by Giuseppe Espa, Roberto Benedetti, Anna De Meo and Salvatore Espa).

2003.3 The Long Swings in Economic Understianding, by Axel Leijonhufvud.

2003.4 Dinamica strutturale e occupazione nei servizi, di Giulia Felice.

2003.5 The Desirable Organizational Structure for Evolutionary Firms in Static Landscapes, by Nicolás Garrido.

2003.6 The Financial Markets and Wealth Effects on Consumption An Experimental Analysis, by Matteo Ploner.

2003.7 Essays on Computable Economics, Methodology and the Philosophy of Science, by Kumaraswamy Velupillai.

2003.8 Economics and the Complexity Vision: Chimerical Partners or Elysian Adventurers?, by Kumaraswamy Velupillai.

2003.9 Contratto d'area cooperativo contro il rischio sistemico di produzione in agricoltura, di Luciano Pilati e Vasco Boatto.

2003.10 Il contratto della docenza universitaria. Un problema multi-tasking, di Roberto Tamborini.

2004.1 Razionalità e motivazioni affettive: nuove idee dalla neurobiologia e psichiatria per la teoria economica? di Maurizio Pugno.

(Rationality and affective motivations: new ideas from neurobiology and psychiatry for economic theory? by Maurizio Pugno.

2004.2 The economic consequences of Mr. G. W. Bush's foreign policy. Can th US afford it? by Roberto Tamborini

2004.3 Fighting Poverty as a Worldwide Goal by Rubens Ricupero

2004.4 Commodity Prices and Debt Sustainability by

Christopher L. Gilbert and Alexandra Tabova

2004.5 A Primer on the Tools and Concepts of Computable Economics by K. Vela Velupillai

2004.6 The Unreasonable Ineffectiveness of Mathematics in Economics by Vela K. Velupillai

2004.7 Hicksian Visions and Vignettes on (Non Linear) Trade cycle Theories by Vela K. Velupillai.

2004.8 Trade, inequality and pro-poor growth: Two perspectives, one message? by Gabriella Berloffa and Maria Luigia Segnana. 
2004.9 Worker involvement in entrepreneurial nonprofit organizations. Toward a new assessment of workers? Perceived satisfaction and fairness by Carlo Borzaga and Ermanno Tortia.

2004.10 A Social Contract Account for CSR as Extended Model of Corporate Governance (Part I): Rational Bargaining and Justification by Lorenzo Sacconi

2004.11 A Social Contract Account for CSR as Extended Model of Corporate Governance (Part II): Compliance, Reputation and Reciprocity by Lorenzo Sacconi

2004.12 A Fuzzy Logic and Default Reasoning Model of Social Norm and Equilibrium Selection in Games under Unforeseen Contingencies by Lorenzo Sacconi and Stefano Moretti

2004.13 The Constitution of the Not-For-Profit Organisation: Reciprocal Conformity to Morality by Gianluca Grimalda and Lorenzo Sacconi 
PUBBLICAZIONE REGISTRATA PRESSO IL TRIBUNALE DI TRENTO 